\title{
An Evaluation of the English Immersion Approach in the Teaching of Finance in China
}

\author{
Ruiqi Zhou \\ School of English for International Business \\ Guangdong University of Foreign Studies \\ 2 Baiyun North Avenue, Guangzhou 510420, China \\ Tel: 86-20-8403-4160Ｅ-mail: rickyzrq@163.com
}

The research is financed by "Creativity in Research Program of Guangdong University of Foreign Studies" (No.: GDUFS 2006-TB-013).

\begin{abstract}
The English immersion teaching approach adopted by SEIB of GDUFS in China was developed on the basis of the immersion theory which was originally developed in North America. Its purpose is to create a learning environment in which the students acquire knowledge in business with English as the main carrier. The adoption of this approach aims to cultivate students with qualifications in both English language proficiency and business knowledge and skills. EDIF is one of the departments within SEIB that has implemented this approach since its establishment in 2001. The paper analyzes the implementation of English immersion teaching approach in the teaching of finance in EDIF from the perspectives of curriculum design, teacher training and recruitment, textbook selection and compilation and classroom teaching. Finally by comparing the results of language proficiency tests of EDIF students and those of the English majors of other colleges in China and by analyzing the employment situation of EDIF graduates, this paper concludes that students of EDIF outperform the other college students in both English language proficiency and employment competitive advantage. This indicates that English immersion teaching approach adopted by EDIF is effective and successful in the cultivation of students in both English proficiency and business knowledge.
\end{abstract}

Keywords: English immersion teaching approach, Teaching of finance, Evaluation

\section{Introduction}

Since its reformation and opening up in 1978, China has witnessed great leap forward in economic development, especially in the area of finance. Furthermore, globalization worldwide and China's entry into WTO at the beginning of this millennium have been accelerating this trend and encouraging more and more foreign financial organizations to set up their branches in China. As a result, there is an increasing demand for personnel in both English proficiency and professional financial knowledge in China. In an attempt to satisfy this potential demand, the English Department for International Finance (EDIF) in the School of English for International Business (SEIB) was established in 2001.

SEIB was among the first few university departments in China who launched a brand new teaching model aiming at nurturing students in both English proficiency and professional business knowledge during their college life --- "English + Business" model. The English immersion teaching approach was developed in order to meet the target of this model. As one of the programs in SEIB, EDIF has been adopting and further enhancing this teaching methodology since its establishment in 2001.

\section{Literature review}

The notion of the English immersion teaching approach originates from the "Immersion in Target Language" teaching methodology. In the early 1960s, a new theory concerning second language acquisition --- learning the target language in an environment where the learner is immersed in the target language --- gained great popularity in Canada. This was first implemented in primary schools in Canada in the acquisition of French as a second language, where English was the first language.

The Immersion teaching approach was mainly developed based on Krashen's Input Hypothesis. According to this theory humans acquire language in only one way --- by understanding messages or by receiving 'comprehensible input' 
(Krashen, 1985). The reason why it is successful is that the learners have been provided with comprehensible input. Cook (1993) argues that for the learner to progress rather than remain static, the input has always to be slightly beyond the level at which he or she is completely at home.

Immersion teaching methodology development was based on the theory that the target language is best acquired if the learner is placed in the target language environment. This placement can be further divided into two types of immersion: complete and partial. The former refers to immersions in all aspects of one's life while the latter is immersion in aspects concerning classroom teaching and learning, such as textbooks, teaching media, classroom discussion, assignments and tests, etc. The purpose of immersion is to immerse the language learners in the target language environment as much as possible so as to improve the language learning efficiency (Cohen, 1998; Cai, 2005).

Ever since then, many a researcher has conducted huge number of studies on the effectiveness of "Immersion in Target Language" teaching approach (Kinberg, 2001; Fred Genessee, 1984 and Swain and Lapkin, 1982, cited in Cai, XL, 2005 ; etc.). The results show that language proficiency of the target language learners who have been immersed in the target language environment has been improved to a significant extent, implying that this language acquisition method is effective.

With the success of immersion theory in Canadian Primary schools, later in the 80s, the University of Ottawa created the "Sheltered Programs" model, also known as "late, late immersion", to introduce the theory into a university context. According to this model, the second language proficiency of the university students is supposed to be acquired in professional courses where the second language is the only carrier of knowledge (Qiang \& Siegel, 2004).

However, unlike the early immersion in target language teaching approach aiming simply to enhance language acquisition, "Sheltered Programs" models attach importance to both language acquisition and knowledge learning. The English Immersion teaching approach adopted by EDIF shares a lot similarity with the "sheltered Programs" model in that business knowledge is learnt together with language proficiency and that English language is learnt as a by-product (Cai, 2001). In other words, English is not learned as a target language, but rather acquired in the process of learning business knowledge. This is in line with Wesche (Professor of the University of Ottwa) in that in the learning process, students are exposed sufficiently to a perfect second language learning environment where their attention is directed to the content of the professional knowledge instead of the language itself (cited in Ma, 1994).

One thing that differs the English immersion teaching approach adopted by EDIF from that by the University of Ottwa is that the former aims to help learners to acquire English as a foreign language in Chinese-speaking culture while the latter intends to help learners to acquire French as a second language in an English-dominating culture. As we know, from the perspective of linguistics, English shares a lot with French while Chinese is largely different from English. Will the immersion teaching approach which works so successful in Canada in the acquisition of French also be effective in China in the learning of English?

To answer this question, this essay is going to first analyze the factors influencing the implementation of the English immersion approach adopted in TEIF throughout the whole teaching and learning process: curriculum design, teacher training and recruitment, textbook selection and compilation and classroom teaching and then evaluate the effectiveness of English immersion teaching approach in Chinese culture in terms of English language proficiency and finance knowledge.

\section{Implementation of the immersion approach in EDIF}

\subsection{Curriculum Design}

Based on the theory of Krashen, when designing curriculum for EDIF, we have taken into consideration the ratio between language courses and finance courses as well as the link between the two types of courses. By so doing we aimed to ensure that students systematically learn professional financial knowledge in English only after they have acquired adequate English competence and a certain amount of basic knowledge in financial terms and concepts.

\subsubsection{Ratio analysis}

Curriculum for EDIF consists of three parts: pathway courses, EDIF courses and Field work (Table 1). EDIF courses consist of 105 credits, 73 for required courses ( $45 \%$ of the total credits), 32 for elective ones ( $19 \%$ of the total). Of the required credits, 67 are for language courses and six for finance courses.

According to Table 1, the ratio of the number of courses in EDIF for English language teaching and finance knowledge teaching is 26:23, including both required and elective courses. However, some courses such as comprehensive English are counted as four courses. They are the same course in nature but are taught for four consecutive semesters varied only in terms of difficulty. Other finance-related courses such as Cross-cultural Communication Skills are counted as language courses. If these factors are considered, the number of finance courses is slightly higher than that of the language courses. What warrants mentioning are the elective credits for EDIF courses. Despite the fact that elective courses only account for 32 credits, students are provided with 28 courses, amounting to 57 credits (14 for English 
elective courses and 43 for finance related courses). This leaves students more freedom in the selection and allocation of courses in the two different disciplines.

\subsubsection{Link between English courses and Finance courses}

The nature of the English Immersion teaching approach calls for a relatively high English proficiency in the students who are involved in this program. As a result, apart from a high benchmark for admission of the students to this program (Note 1), a great deal of importance has been attached to the improvement of students' English language ability (including both English language knowledge and the skills to use English in financial activities) before they start to learn business knowledge. The purpose is to ensure a smooth transition from the learning of language to the learning of finance knowledge in English. To achieve this goal, we have been trying to design different courses at different learning stages, with a view to a reasonable and logical connection between language courses and finance courses.

As is shown in Table 2, as the main task for the first-year students of EDIF is to improve their English proficiency as a whole, the courses designed are mostly language-orientated, with five required language courses amounting to 26 credits. There are only ten Business-related credits, mainly for such courses as Advanced Mathematics, Statistics, etc. The second learning phase involves language-orientated courses supplemented by basic finance courses. This phase focuses more on the cultivation of abilities in English language use and communication skills in the general financial environment. There are six English courses amounting to 20 credits and four basic finance courses amounting to four required credits and five elective credits respectively. Of the six English courses, three are transitional courses such as Finance English, Cross-cultural Communication and Readings from Business-related Newspapers and Magazines.

More finance courses are added to the curriculum at the third stage, while the number of language courses is reduced. There are as many as 10 courses concerning finance or other business knowledge available to junior students, most of which are elective courses. A further reduction on language courses is seen in the last phase. In the first term of the fourth year, except for two language courses such as Advanced English Writing and English-Chinese/Chinese-English Interpreting, there are five business courses amounting to ten credits available for students to choose from. The second term is totally devoted to field work and dissertation writing. Students are required to write a dissertation in English about finance and related business knowledge, the purpose of which is to enhance their comprehensive ability in the use of English language knowledge and in the application of their business knowledge to the solution of specific problems.

We believe that language courses and finance courses in English are complementary to each other, not independent of each other. Therefore, in curriculum design, a reasonable ratio of and a logical and smooth connection between the courses of both English discipline and finance discipline are the keys to the success of "English + Business" education model.

\subsection{Recruitment and training of teaching staff}

As has been discussed above, students of EDIF program need to learn both English as a language and also knowledge related to finance or other business with English as the carrier. This of course calls for higher qualification of teachers involved in this program. Language teachers may be qualified for language courses or finance-related language courses after receiving a certain period of training. However, for professional finance courses carried by English, we need teachers who are qualified in this field and who also have adequate English proficiency. Therefore, the recruitment and maintenance of a team of qualified teaching staff is an important task for EDIF.

At the time when EDIF was established, most of its teaching staff was language teachers with good command of English proficiency but limited knowledge in business disciplines. On the other hand, in spite of there being a large number of professional business teachers in China, relatively poor English proficiency of these teachers makes it hard for them to be qualified for teaching in our program. Hence, with a view to ensuring high teaching quality and the further implementation of our pedagogic beliefs we make it clear to our existing young teachers that they need to shape their teaching and research fields. And to be qualified, they are also expected to obtain relevant master's or doctor's degrees in their selected fields. Aside from this, we have also tried hard to recruit new teaching staff from home and abroad.

Our principles for the training and recruiting of teaching staff are mainly as follows:

1) encouraging teachers to attend lectures and courses given by distinguished professors in the field of finance and related business in our university

2) encouraging and financing teachers aged under 40 to pursue further master's or doctor's degrees in the field of finance or business at home and abroad

3) recruiting new finance staff with higher academic degree and teaching and research ability and

4) hiring senior professors in finance from abroad.

As long as 7 years' practice of these principles has helped us improve the quality of the teaching staff. As can be seen 
from Table 3, 99\% of all teachers in SEIB have obtained a master's or doctor's degrees. Of these 35 are teachers of finance. The number of teachers who have obtained master's degree or doctor's degrees in both English language and business is 8. Most of the teachers in SEIB have learned English as a second language or have lived or studied in English-speaking countries for sometime, which helps to meet the requirement for the teaching of business knowledge in English.

As far as EDIF is concerned, as is shown in Table 4, there are altogether 22 teachers who teach finance in English. Nine of these are masters in finance and four of them are doctoral students in finance, occupying $41 \%$ of all professional business teachers.

A survey by Cai (2002) on the satisfaction with teaching in EDIF may more or less explain the positive result of the recruitment and training of qualified teaching staff. According to him, $77 \%$ of the students surveyed felt satisfied with teachers' performance in class and their knowledge in both professional field and language.

\subsection{Textbook selection and compilation}

Another key factor that determines the effectiveness of the English Immersion teaching approach in EDIF is the selection and development of textbooks that are compiled in English. At present, the textbooks adopted in EDIF program mainly fall into three types: 1) those compiled by teachers at home; 2) those compiled by teachers in EDIF; and 3) those introduced from abroad.

Most textbooks related to language teaching are in the first category. However, in order to ensure a more natural and smooth transition from pure English courses to professional knowledge courses, a group led by Professor Cai of SEIB has compiled a new series of textbooks for comprehensive English course: Business English: an Integrated Course. The objective of the compilation of these books is to help freshmen and sophomores to familiarize themselves with business terms in English, business English stylistics and discourses with business characteristics, thus providing them with a solid foundation for the learning of professional knowledge carried by English later on.

As far as the finance textbooks compiled in English are concerned, of the 12 finance courses in the EDIF program, eight select textbooks introduced from abroad, three use those compiled by the teaching staff of EDIF and one chooses those compiled by teachers at home other than EDIF.

To ensure the immersion of finance courses in English to its largest extent, the choice of textbooks introduced from abroad is critical and essential. The reasons are as follows: First of all, that these textbooks are compiled by native English-speaking experts ensures the appropriateness of the English language. Secondly, that most textbooks are compiled by authoritative experts in relative business areas guarantees the authoritativeness of the textbooks. Thirdly, most textbooks introduced from abroad are supplemented with further reading materials, case studies and other exercises which can help students not only in the learning of knowledge but also in the application of knowledge.

Because of these advantages, the textbooks for EDIF business courses are mostly those from abroad. However, we also apply the following principles in the selection of these textbooks:

1) authoritative --- textbooks should be compiled by authoritative experts in relative fields;

2) up-dated --- textbooks should include up-dated theories and knowledge in certain fields;

3) appropriate --- the language of the textbooks should be appropriate for students of EDIF; and

4) operational --- textbooks should be supplemented with teaching discs and exercises.

In teaching practice, we also have encouraged teachers to use cases or concepts which are more closely related to Chinese business practice. $62 \%$ of the subjects in a survey conducted by Zhu (2005) reported that a combination of finance textbooks from abroad and at home helped produce a better and desired result in the students.

\subsection{Teaching Activities}

The aim of improving teaching activities is to better live out the target for personnel cultivation in EDIF. In the 7 years' teaching practice in EDIF program, we have tried to adopt a combination of different teaching methods such as lecturing, seminar, case analysis, task-based teaching, social practice, etc.

Some EDIF courses require that students should have a certain level of knowledge in science, especially in mathematics, which inevitably makes it rather difficult for students of arts whose mathematics is relatively poor. As a result, it arouses a sense of fear and anxiety in quite a few students. As is proposed by Krashen (1985) in his "affective filter" hypothesis, the learner is "unmotivated, lacking in self-confidence, or anxious if the affective filter is so high up that it prevents input from getting through". In view of this, teachers are careful in creating a relaxed and comfortable learning environment. For example, some of the teachers start their teaching with warming-up activities such as cases or problems in financial fields with a view to cultivating students' interest in financial knowledge, stimulating their enthusiasm for learning and arousing their motivation and building their confidence in finance courses. While in class, teachers lay stress on interactive and communicative methods of teaching. They use various teaching activities such as 
presentation and seminar discussion to help students actively involved into their learning process.

Finance is a discipline that is closely related to practice, and case study is seen to be a sound means to relate financial theory to practice. Therefore, since its establishment by Christopher Columbus Langdell in the 1870s (Han, 2005), as a teaching activity, case studies have been widely adopted in the teaching of finance and other business disciplines. The aim of case studies is to help students improve their ability in the application of knowledge acquired and their ability in analysis, inference, induction and summarization. Therefore, it is understandable that case analysis ranks first in the list of the most highly adopted teaching activities by teachers of EDIF. A questionnaire conducted in SEIB shows that $95.7 \%$ of the students are satisfied with case analysis teaching activity (Han, 2005).

Finance is also a discipline that is highly theoretical, hence problem/project-based learning and task-based learning teaching methods are also widely adopted by our teaching staff. For example in the teaching process, teachers will design some related questions for students to discuss in groups and then report to the class. Or for each semester, they will design research questions for students to prepare after class. After instruction from the teachers, students are expected to conduct a mini-research on one or two of them in small groups and write a term paper based on the results. These ways of teaching on one hand help students actively involved in their learning process, on the other hand help them practice their ability in the application of the knowledge learned, in the analyses of the problems proposed and in the communication skills required in financial environment.

What needs to be noticed is that throughout the whole teaching process, teachers of EDIF program are required to ensure that English is the main carrier of classroom teaching and learning. With a solid English language foundation built at an earlier stage and the activities and strategies teachers adopted for the reduction of anxiety in classroom teaching, students of EDIF gradually gain confidence in learning the subjects of finance given in English.

\section{Evaluation}

The evaluation of students' ability in EDIF can be conducted from two perspectives: English proficiency and finance knowledge. The former can be measured by a comparison of the results of TEM 4 and TEM 8 between EDIF students and English majors of other schools and universities while the latter can be assessed by analyzing the employment competitiveness of the graduates in EDIF as no relevant national financial test is available presently. (Note2)

As is shown in Table 5, the results of both TEM 4 and TEM8 of EDIF students from 2004 to 2006 are far better than English majors of the other Chinese colleges. This indicates that students of EDIF are at a higher level in terms of their English language proficiency despite the fact they devote half less of their time to the study of English language courses than those English majors of other colleges, which to some extent implies the effectiveness of English immersion teaching approach in the acquisition of English language.

According to Table 6, all graduates from 2004 to 2006 were either employed or pursuing further education at home or abroad. Most of the employed students have their jobs in large promising enterprises of foreign ventures, joint ventures or joint cooperation and other big financial organizations, such as KPMG (Klynveld Peat Marwick Goerdeler), PWC (PricewaterhouseCoopers), EY (Ernst \&Young), and DTT(Deloitte Touche Tohmatsu).

In China, with the expansion in the enrollment of higher education, more and more college graduates are faced with ever intensifying threat of unemployment. For example, according to People's daily, the employment rate of college graduates in 2006 is as low as 73\%. Meanwhile, graduates of EDIF not only are able to find a job, but more importantly, able to find a decent job, which more or less indicates that the graduates cultivated by EDIF's "Business + Business" model is in line with the need for talents in the labor market.

\section{Conclusions}

From the curriculum design to the training and recruiting of teaching staff, to the choice and compilation of textbooks and finally to the adoption of teaching activities, EDIF has succeeded in implementing the English immersion teaching approach in the entire process of our teaching practice. The evaluation of the implement of the new model (English + Finance) and English immersion teaching approach catering for this model adopted by EDIF has proven to be effective in cultivating personnel qualified in both English language proficiency and finance knowledge and skills, therefore is accordance with the requirement for economic globalization.

However, as a new model, it is also confronted with many difficulties and is far from perfect. There lacks adequate preparation courses before courses in finance. Difficulty in recruiting and maintaining staff qualified both in English and Finance poses another problem. Some textbooks compiled by domestic teachers are to an extent not so satisfied and those introduced from abroad are somewhat deviated from Chinese finance practice. Aside from all these, the means of evaluation of students' ability in finance is not scientific enough, leaving large room for the conduction of future research. However, despite all these difficulties, EDIF has made the first step forward and has every confidence in moving even further. 


\section{References}

Cai Xiaoli. (2005). On the English Immersion Approach to Program of International Business Administration. International Economics and Trade Research, 21, 62-65.

Cai Yun. (2001). Effective ways in the cultivation of interdisciplinary talents. Foreign Languages and Their Teaching, 4, 33-35.

Cai Yun. (2005). The Design an Implementation of English Immersion Approach: Evaluation of BBA Program of GDUFS. International Economics and Trade Research, 21, 4-8.

Cohen D. Andrew. (1998). Strategies in Learning and Using a Second Language. London: Longman.

Cook V. (1993). Linguistics and Second Language Acquisition. London: Macmillan.

Han, Yonghong. (2005). Thoughts on Teaching Law Courses in English. International Economics and Trade Research, 21, 40-43.

Kinberg, M. (2001). Perspective on Foreign Language Immersion Programs. The Edwin Mellen Press.

Krashen, S.D. (1985). The Input Hypothesis: Issues and Implications. London: Longman.

Ma, Zhenduo. (1994). Viewing second language education in Canadian universities from the University of Ottawa [C]. Research on Canadian Education. Sian: Shanxi Normal School Publishing House.

People's Daily. (2006). Time to abolish the collection of the employment rate of college graduates. [on line] Available: http://news3.xinhuanet.com/edu/2006-08/07/content_4927660.htm (August 7, 2006).

Qiang, Haiyan \& Siegel Linda. (2004). Introduction of the Development of Second Language Immersion Programs in Canada. Comparative Education Review, 7, 1-7.

Zhu, Wenzhong. (2005). Investigation and Analysis of the English Immersion Education. International Economics and Trade Research, 21, 50-53.

\section{Notes}

Note 1. This is measured by the results of National Entrance Examination in China.

Note 2. TEM (Test for English Major) is a national test in China administrated by National Advisory Commission on Foreign Language Teaching in Higher Education (NACFLT) for English Majors nationwide. TEM4 is supposed to be taken by sophomores while TEM 8 by seniors. The Certificate is issued by NACFLT and is commonly used.

Table 1. Credit Distribution for EDIF Curriculum

\begin{tabular}{|c|c|c|c|c|}
\hline \multicolumn{3}{|c|}{ Courses } & Credits & $\%$ of total credits \\
\hline \multirow{2}{*}{ Pathway Courses } & \multicolumn{2}{|c|}{ Required } & 28 & 17 \\
\hline & \multicolumn{2}{|c|}{ Elective } & 18 & 11 \\
\hline \multirow{3}{*}{ EDIF Courses } & \multirow[b]{2}{*}{ Required } & English & 67 & 41 \\
\hline & & Finance & 6 & 4 \\
\hline & \multicolumn{2}{|c|}{ Elective } & 32 & 19 \\
\hline Field Work & & & 14 & 8 \\
\hline Total & & & 165 & 100 \\
\hline
\end{tabular}


Table 2. Curriculum Design of EDIF in Terms of Learning Phases

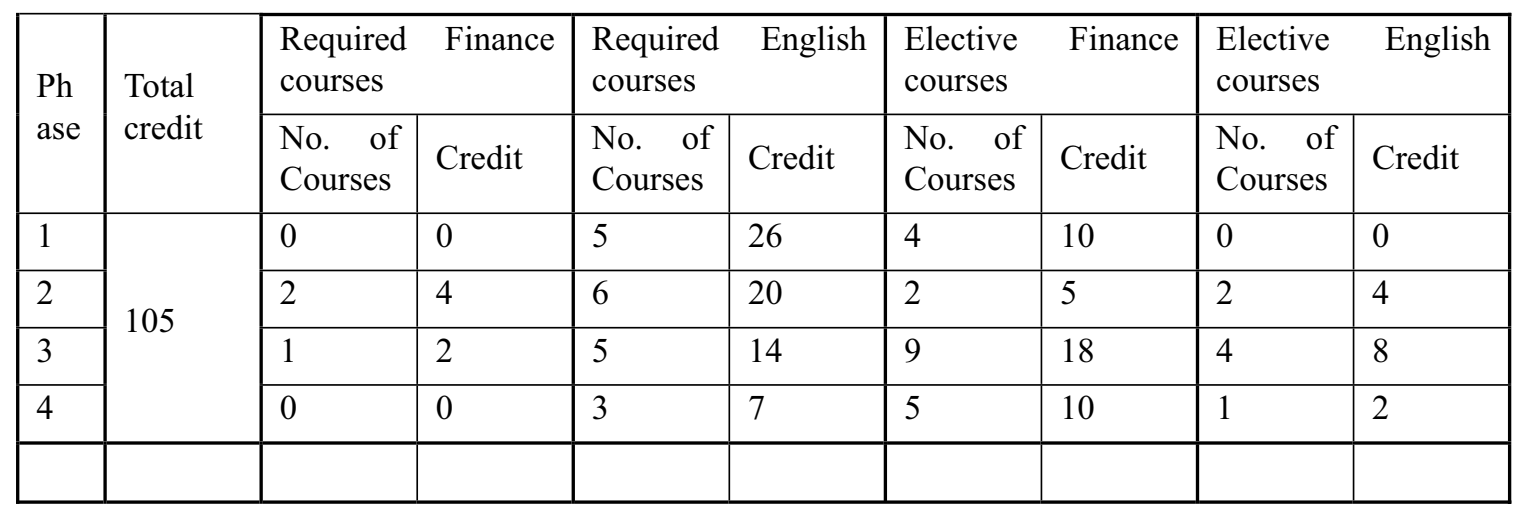

Table 3. Teaching Staff in SEIB

\begin{tabular}{|c|c|c|c|}
\hline Academic Degree & Discipline & Number & Percentage \\
\hline \multirow[t]{2}{*}{ Bachelors } & Linguistics & 2 & 2 \\
\hline & Linguistic and Literature & 54 & 51 \\
\hline Masters & TEIB & 6 & 6 \\
\hline (13 Doctors-to-be & Business & 25 & 24 \\
\hline \multirow[t]{3}{*}{ Included) } & Linguistic + Business & 8 & 8 \\
\hline & Sub-total & 93 & 89 \\
\hline & Linguistics & 8 & 8 \\
\hline \multirow[t]{2}{*}{ Doctors } & Business & 2 & 2 \\
\hline & Sub-total & 10 & 10 \\
\hline & Total & 105 & 100 \\
\hline
\end{tabular}

Table 4. Teaching Staff in EDIF

\begin{tabular}{clc}
\hline Academic Degree & \multicolumn{1}{c}{ Discipline } & No. \\
\hline Master & Finance and Accounting & 9 \\
& Others & 11 \\
& Sub-total & 20 \\
\cline { 2 - 3 } & Economics & 2 \\
\hline Doctor & Total & 22
\end{tabular}

Table 5. A Comparison of Results of TEM4 and TEM8 between EDIF students and English majors in other Chinese colleges

\begin{tabular}{|c|c|c|c|c|c|c|}
\hline & \multicolumn{2}{|c|}{2004 pass $\%$} & \multicolumn{2}{|c|}{2005 pass $\%$} & \multicolumn{2}{|c|}{2006 pass $\%$} \\
\hline & TEM4 & TEM8 & TEM4 & TEM8 & TEM4 & TEM8 \\
\hline Other colleges & 87 & 80 & 76 & 83 & 79 & 74 \\
\hline EDIF & 92 & 92 & 100 & 88 & 98 & 80 \\
\hline
\end{tabular}


Table 6. 2004 -2006 EDIF graduates employment situation

\begin{tabular}{|c|c|c|c|c|c|}
\hline Year & Employed & $\begin{array}{c}\text { Further education at } \\
\text { home }\end{array}$ & Further education abroad & Total & Employment \% \\
\hline 2004 & 71 & 11 & 9 & 91 & $100 \%$ \\
\hline 2005 & 42 & 5 & 2 & 49 & $100 \%$ \\
\hline 2006 & 24 & 1 & 0 & 25 & $100 \%$ \\
\hline
\end{tabular}

